IZA DP No. 7933

An Experimental Test of a Search Model under Ambiguity

Takao Asano

Hiroko Okudaira

Masaru Sasaki

January 2014 


\title{
An Experimental Test of a Search Model under Ambiguity
}

\author{
Takao Asano \\ Okayama University \\ Hiroko Okudaira \\ Okayama University \\ Masaru Sasaki \\ Osaka University \\ and IZA
}

Discussion Paper No. 7933
January 2014

IZA
P.O. Box 7240
53072 Bonn
Germany

Phone: +49-228-3894-0

Fax: +49-228-3894-180

E-mail: iza@iza.org

Any opinions expressed here are those of the author(s) and not those of IZA. Research published in this series may include views on policy, but the institute itself takes no institutional policy positions. The IZA research network is committed to the IZA Guiding Principles of Research Integrity.

The Institute for the Study of Labor (IZA) in Bonn is a local and virtual international research center and a place of communication between science, politics and business. IZA is an independent nonprofit organization supported by Deutsche Post Foundation. The center is associated with the University of Bonn and offers a stimulating research environment through its international network, workshops and conferences, data service, project support, research visits and doctoral program. IZA engages in (i) original and internationally competitive research in all fields of labor economics, (ii) development of policy concepts, and (iii) dissemination of research results and concepts to the interested public.

IZA Discussion Papers often represent preliminary work and are circulated to encourage discussion. Citation of such a paper should account for its provisional character. A revised version may be available directly from the author. 
IZA Discussion Paper No. 7933

January 2014

\section{ABSTRACT}

\section{An Experimental Test of a Search Model under Ambiguity}

This paper's objective is to design a laboratory experiment to explore the effect of ambiguity on a subject's search behavior in a finite-horizon sequential search model. In so doing, we employ a new approach to observe the potential trend of reservation points that is usually unobserved. We observe a significant dip in a trend of reservation points when subjects are faced with ambiguity over wage distributions.

JEL Classification: C91, D81

Keywords: experiment, search model, ambiguity, reservation wage

Corresponding author:

Masaru Sasaki, Graduate School of Economics

Osaka University

1-7 Machikaneyama

Toyonaka, Osaka 560-0043

Japan

E-mail: sasaki@econ.osaka-u.ac.jp 


\section{Introduction}

In the literature on job search, it is well known that an increase in risk makes individuals search for longer periods. However, it can also be considered that an increase in "uncertainty" about the prospect of labor market conditions makes individuals more cautious, which then makes them search for shorter periods because they expect that they would not obtain more-appealing job offers in the future. Considering the notion of ambiguity (Knightian uncertainty) differentiated from that of risk, Nishimura and Ozaki (2004) theoretically show that an increase in ambiguity decreases the reservation wage, thereby inducing individuals to search over a shorter period. ${ }^{1}$ The purpose of this paper is to design a laboratory experiment of a finite-horizon sequential search model with ambiguity in the sense that an offer distribution is unknown, and to ascertain whether the result of Nishimura and Ozaki (2004) is supported by the experimental results. ${ }^{2}$

\section{Experimental design}

An individual subject faces games of 20 rounds by way of a finite-horizon sequential search model in which recall is not allowed. A point is drawn randomly from a given point distribution by a computer faced by a subject in the first round, and then the subject clicks either 'accept' or 'reject' buttons on a screen. ${ }^{3}$ If the subject accepts the point, the search activity is concluded, and the accepted point is converted to the payment in this game. If the subject rejects the point, he or she moves on to the

\footnotetext{
${ }^{1}$ Nishimura and Ozaki (2004) apply the Multiple-prior Expected Utility (MEU) theory and its variants to the job search model. See Gilboa and Schmeidler (1989) for details about MEU theory.

${ }^{2}$ Laboratory experiments are a popular way of testing theoretical predictions from a job search model (ex. Cox and Oaxaca, 1989; Brown et.al, 2011). In the context of ambiguity in experiments, see Chen et.al. (2007) and Viefers (2012).

3 We here use "point” to put a search model to the test to prevent subjects from associating "wage” with job search.
} 
second round where a point is drawn again from the given point distribution. The subject can continue to search until the 20th round, and if the subject rejects a point drawn in the last round, the search activity is automatically terminated, and no point is obtained. Points were not discounted over the rounds.

To represent the effect of ambiguity, we employ two types of point distribution. In the first treatment (T1), subjects are provided with common information of a uniform distribution with a lower bound of 1 and an upper bound of 3000. In the second treatment (T2), the subjects are told that, in each round, the computer randomly selects a point from an unknown distribution except that it has a lower bound of 1 and an upper bound of 3000, and that a different distribution may be randomly selected every round by the computer. This prevents the subjects from updating their information about the true point distribution in a Bayesian manner and rules out the learning effect on search behavior. Throughout the experiment, subjects are not informed about the true point distribution, but to facilitate a comparison of (T1) and (T2), the distribution is actually set the same as the uniform distribution with a lower bound of 1 and an upper bound of $3000 .^{4}$

While this accept-or-reject type experiment is simple and easy to implement, it provides us with little information on how the ambiguity would change the trend of reservation points up to the final round. We could ask subjects to directly type in their reservation point instead of asking them to click on accept or reject buttons, but this would not help us much to test precisely the theoretical result obtained by Nishimura and Ozaki (2004). There are two reasons for this. First, most subjects tend to finish searching long before the final round in laboratory experiments, according to the past

\footnotetext{
${ }^{4}$ If the distribution actually changes every round, we cannot identify whether the difference between the two treatments in search duration is attributable to ambiguity or to the variations in distributions.
} 
literature (Schunk and Winter, 2009). Second, the lower the reservation point, the earlier the subject finishes the search, thereby creating upward bias on the reservation points as the game approaches the final round because the subject whose reservation point is higher survives in the latter round.

We supplement our experiment with another type of treatment to observe the potential but true trend in reservation points. In particular, the third treatment (T1-commit) is a search activity in which a subject ex ante commits to a series of reservation points, assuming that their points are drawn from the uniform distribution with a lower bound of 1 and an upper bound of 3000. The actual experiment proceeded as follows. First, the subjects were told to type in the minimum point that they are willing to accept (i.e., reservation point) in the first round, and then fill in the reservation point in the second round, provided that they had moved on to the second round. The same procedure is undertaken round by round until the 20th round. After typing 20 numbers of the reservation point, each subject clicks the button to start the actual search. The computer randomly picks a first-round point and compares it with the first-round reservation point that a subject had already typed in. If the point drawn is lower than the first-round reservation point, the search activity continues with the computer drawing a second-round point. Otherwise, the computer stops searching and gives the subject the drawn point. The computer continues the same procedure until the search ends.

The last treatment (T2-commit) is similar to T1-commit, except that subjects are faced with the unknown distribution as in T2.

One obvious challenge with this method is the reliability of reservation points. Since subjects commit ex ante before actually playing a game, the observed reservation 
point may not necessarily represent their true reservation point. To address this point, we compare the reservation points in T1-commit (T2-commit) to their search outcome in T1 (T2), and examine whether the observed reservation points are consistent with their actual responses in a simple reject-or-accept search game. In particular, we define a subject as having consistent behavior in T1-commit (T2-commit) if the following conditions are satisfied: ${ }^{5}$

- for any given round in all T1 (T2) games, a subject accepts the offered point if the offered point is no less than the reservation point at the corresponding round of T1-commit (T2-commit); and

- for any given round in all T1 (T2) games, a subject rejects the offered point if the offered point is lower than the reservation point at the corresponding round of T1-commit (T2-commit).

We evaluate the effect of ambiguity on a trend in reservation points by limiting our sample to observations with consistent behavior.

Our experiment consists of two sessions. Each experimental session consists of 11 games and one practice game as follows:

Session 1: (T1-practice), (T1), (T2), (T1), (T2), (T1-commit), (T1), (T2), (T1), (T2), (T1), (T2-commit).

Session 2: (T1-practice), (T2), (T2), (T2), (T2), (T2-commit), (T1), (T1), (T1), (T1), (T1), (T1-commit).

The experiment was conducted in the experimental laboratory at Osaka

\footnotetext{
${ }^{5}$ We assume that a reservation point at each round in $\mathrm{T} 1$ (T2) equals the reservation point at the corresponding round of T1-commit (T2-commit).
} 
University. Subjects consisted of 44 undergraduate and graduate students (21 in session 1 and 23 in session 2). The experiments were run entirely on computers using Z-tree (Fischbacher, 2007). At the end of the experiment, one of the results from the 11 games was randomly selected to determine the final payment, in which one experimental point is converted to JPY1.

\section{Results}

Fig. 1 plots the average survival rate of the search activity at each round. Averages are calculated from observations in reject-or-accept type treatments only (T1 and T2). The graph clearly shows the negative effect of ambiguity on the proportion of subjects who remain searching. Interestingly, no significant difference was observed in the first two rounds, but the negative effect of ambiguity became gradually larger as the game went on, with the maximum difference being 11.4 percentage points at the seventh round. The lower survival rate also indicates the shorter search duration. Column (1) of Table 1 reveals that the average subject continues searching for 6.81 rounds in $\mathrm{T} 1$, but for 5.63 rounds in $\mathrm{T} 2$.

However, Fig. 1 is only suggestive of accepting the theoretical result obtained by Nishimura and Ozaki (2004). One wonders whether subjects set themselves a lower reservation point in $\mathrm{T} 2$ than in $\mathrm{T} 1$ or happened to be offered lower points in $\mathrm{T} 2$ than in T1. To distinguish the two causes, we need to observe the true trend in reservation points and confirm that subjects finished their search early precisely because they set lower reservation points under the unknown distribution.

Fig. 2 reveals our results on average reservation points. While we observe no big difference in reservation points on the left panel of Fig. 2, we found a large dip on the 
trends of reservation points on the right panel, in which the sample is limited to consistent observations. The divergence becomes the largest in the 18th round, where the average reservation point is 1847.8 under the uniform distribution whereas it is 1532.4 under the unknown distribution.

\section{Concluding remarks}

The experimental design proposed in this paper allows us to extract the potential and true trend of reservation points and to confirm directly that subjects reduce their reservation point in the presence of ambiguity about the point distributions, thus supporting the theoretical result shown by Nishimura and Ozaki (2004). We formally tested the hypothesis by controlling for the points obtained in the previous game, a set of individual, round and period dummies and also a session dummy, as shown in Appendix Tables. None of these robustness tests changes our results.

\section{Acknowledgement}

The authors thank Takanori Adachi, Keiko Aoki, Yasuyo Hamaguchi, Youichiro Higashi, Yoichi Hizen, Chiang Hui-Yu, Keisuke Kawata and the participants in the JEA Meeting and the International Workshop on Experimental Economics and Finance. Financial support from the Zengin Foundation for Studies on Economics and Finance, MEXT (No. 23530275) and GCOE and ISER grant (Osaka University) are greatly acknowledged. All errors are our responsibility.

\section{References}

Brown, M., C.J. Flinn, and A. Schotter (2011): "Real-Time Search in the Laboratory and the Market,” American Economic Review 101:2, 498-974. 
Chen, Y, P. Katuščák, and E. Ozdenoren (2007): “Sealed Bid Auction with Ambiguity: Theory and Experiments,” Journal of Economic Theory 136, 513-535.

Cox, J. C. and R. L. Oaxaca (1989): "Laboratory Experiments with a Finite-Horizon Job-Search Model,” Journal of Risk and Uncertainty 2, 301-330.

Fischbacher, U. (2007) “Z-tree zurich toolbox for ready-made economic experiments,” Experimental Economics 10, 171-178

Gilboa, I. and D. Schmeidler (1989): “Maxmin Expected Utility with Non-Unique Priors,” Journal of Mathematical Economics 18, 141-153.

Nishimura, K. G. and H. Ozaki (2004): “Search and Knightian Uncertainty,” Journal of Economic Theory 119, 299-333.

Viefers, P. (2012) "Should I Stay or Should I Go? A Laboratory Analysis of Investment Opportunities under Ambiguity,” DIW Berlin Discussion Paper, No. 1228.

Table 1 Summary Statistics

\begin{tabular}{ccc}
\hline & $\begin{array}{c}(1) \\
\text { All } \\
\text { observations }\end{array}$ & $\begin{array}{c}(2) \\
\text { Consistent } \\
\text { observations }\end{array}$ \\
\hline $\begin{array}{ccc}\text { Average search durations } \\
\text { T1 }\end{array}$ & \\
T2 & 6.81 & 6.18 \\
T1-commit & 5.63 & 5.33 \\
T2-commit & 7.20 & 8.06 \\
& 6.16 & 4.40 \\
N. of observations (game-level) & & \\
T1-commit & $44[100 \%]$ & $16[36.4 \%]$ \\
T2-commit & $44[100 \%]$ & $20[45.5 \%]$ \\
\hline
\end{tabular}




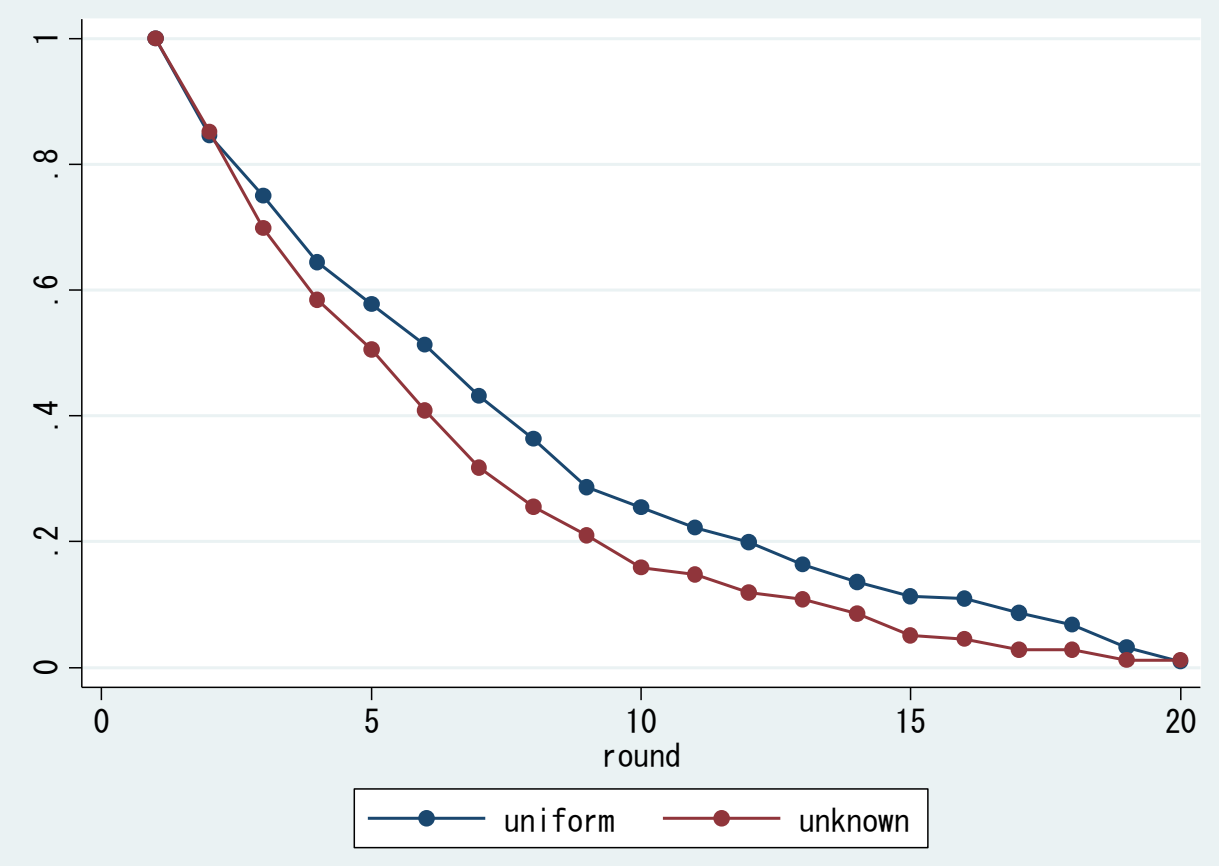

Fig. 1 Average Survival Rate (sample = game-level observations from T1 and T2)

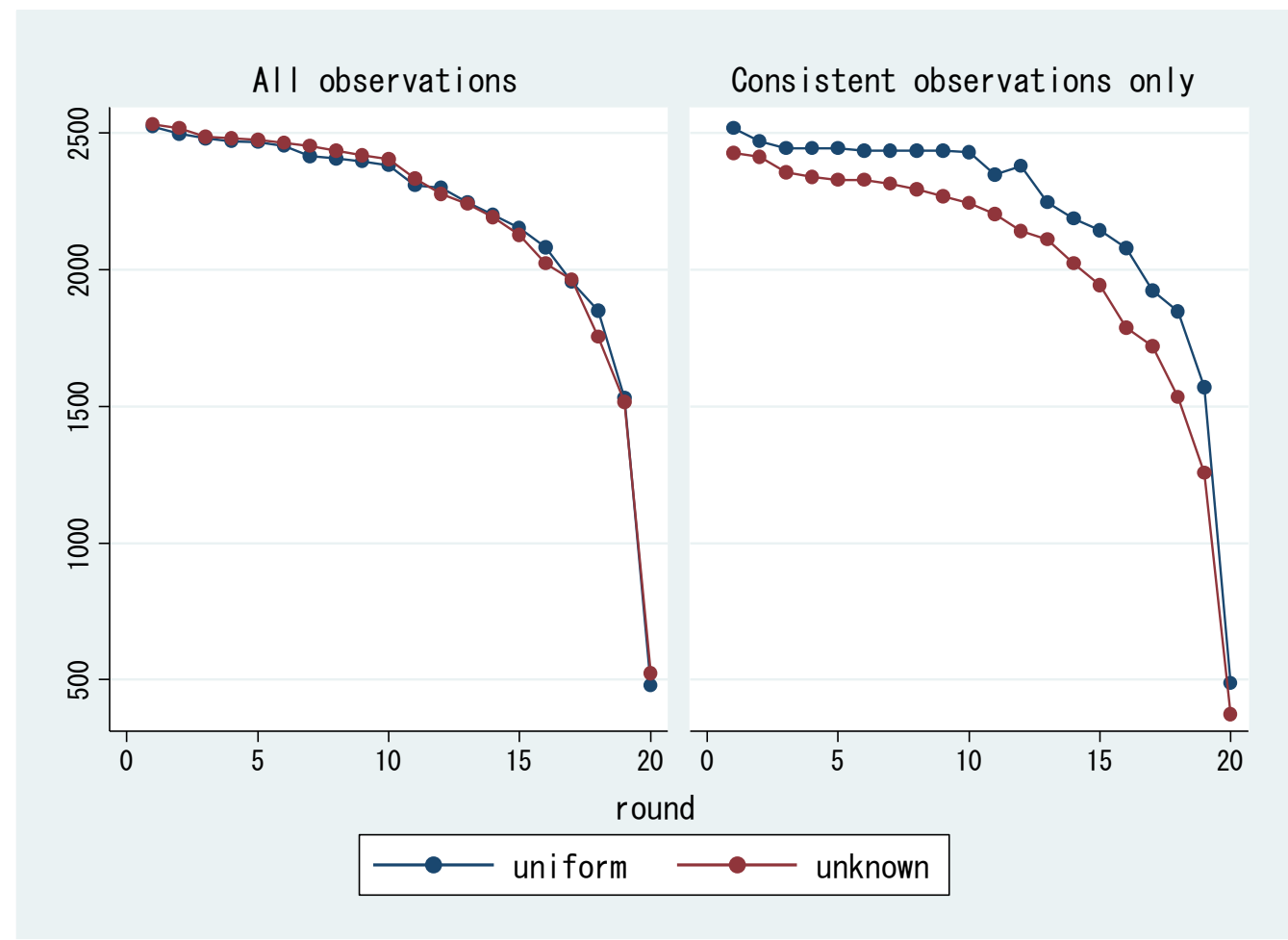

Fig. 2 Average Reservation Points (sample = round-level observations from T1-commit and T2-commit) 


\section{Appendix Table 1}

Search Duration under Knightian Uncertainty

\begin{tabular}{lccc}
\hline & \multicolumn{3}{c}{ Y Sample = T1 and T2 } \\
\cline { 2 - 4 } & $(1)$ & $(2)$ & $(3)$ \\
\hline \multirow{2}{*}{ Knight $(=1)$} & $-1.1784^{* * *}$ & $-1.1784 * *$ & $-0.8330 *$ \\
& $(0.4373)$ & $(0.4506)$ & $(0.4631)$ \\
Points obtained in the previous & & & 0.0015 \\
game & & & $(0.0010)$
\end{tabular}

Subject dummies

No. Yes. Yes.

Session dummy

No. Yes. Yes.

\begin{tabular}{lccc}
\hline R-squared & 0.0141 & 0.2658 & 0.2847 \\
$\mathrm{~N}$ & 396 & 396 & 352 \\
\hline
\end{tabular}

Note: Robust standard errors clustered by subject are in parentheses. *** $1 \%$, ** 5\%, * $10 \%$ significance. Sample consists of game-level observations from all $\mathrm{T} 1$ and $\mathrm{T} 2$ treatments. 


\section{Appendix Table 2}

Knightean Uncertainty on Reservation Point

\begin{tabular}{lcccc}
\hline & \multicolumn{4}{c}{ Y = Reservation point } \\
& \multicolumn{4}{c}{ Sample $=$ T1-commit and T2-commit (round-level observations) } \\
\cline { 2 - 5 } & $(1)$ & $(2)$ & $(3)$ & $(4)$ \\
\hline & All obs. & All obs. & Consistent obs. & Consistent obs. \\
Knight (=1) & 0.9654 & -9.8551 & $-52.78755^{* * *}$ & $-55.20744^{* * *}$ \\
Average points obtained in & $(20.9478)$ & $(19.4889)$ & $(13.5541)$ & $(8.0729)$ \\
the previous games & & $0.2491)^{* *}$ & & $0.1422{ }^{* * *}$ \\
& & $(0.0932)$ & & $(0.0150)$ \\
Subject dummies & & & & \\
Round dummies & Yes. & Yes. & Yes. & Yes. \\
Session dummy & Yes. & Yes. & Yes. & Yes. \\
Period dummies & Yes. & Yes. & Yes. & Yes. \\
& Yes. & Yes. & Yes. & Yes. \\
\hline Adjusted R-squared & & & & 0.822 \\
$\mathrm{~N}$ & 0.824 & 0.826 & 0.822 & 720 \\
\hline
\end{tabular}

Note. Robust standard errors clustered by subjects are in parentheses. $* * * 1 \%, * * 5 \%, * 10 \%$ significance.

Sample consiste of round-level obervations from T1-commit and T2-commit treatments. Consistent observations indicate the observations from T1-commit or T2-commit games in which subjects took

consistent behavior for a given round in all corresponding reject-or-accept type games (all T1 or T2 games). For each game, subject takes a consistent bahavior if, for any given round, a subject accepts a pont drawn in $\mathrm{T} 1$ (T2) when the point is no less than the corresponding reservation point in T1-commit (T2-commit), and, if for any given round, a subject rejects a point drawn in T1 (T2) when the point is lower than the corresponding reservation point in T1-commit (T2-commit). 